\title{
Dessecação Química da Soja em Diferentes Estádios Fenológicos para Antecipação da Colheita
}

\section{Chemical Desiccation of Soybean in Different Phenological Stages for Early Harvest}

\author{
André Roberto da Silva'; Andrea Scaramala; Guilherme Renato Gomes ${ }^{a}$; Gabriela S. Machineski*a
}

${ }^{\mathrm{a} U n o p a r . ~ P R, ~ B r a s i l . ~}$

*E-mail: gabymachine@yahoo.com.br

\begin{abstract}
Resumo
A prática da dessecação pré-colheita em lavouras de soja vem sendo cada vez mais empregada, pois proporciona benefícios como antecipação da colheita, controle de plantas daninhas e maior uniformidade na maturação da cultura. Todavia, deve-se posicionar a aplicação do herbicida em estádios fenológicos da cultura que não prejudique o enchimento de grãos e, consequentemente, a produtividade. Dessa forma, o presente trabalho teve como objetivo avaliar o efeito da aplicação do dessecante Diquat, em diferentes estádios reprodutivos, sobre a perda de umidade e a produtividade e a consequente antecipação da colheita da soja. O experimento foi instalado em área homogênea em delineamento inteiramente casualizado, com três repetições. Os tratamentos testados foram aplicação do herbicida Diquat nos estádios $R_{6}$, $R_{7}$ e $R_{8}$ e um controle sem aplicação de herbicida. As variáveis analisadas foram o teor de umidade dos grãos após dessecação, a massa de mil grãos e a produtividade. Os dados foram submetidos a análise de variância. As médias dos teores de umidade foram comparados, par a par com o controle, pelo teste $\mathrm{t}$ de Student. As médias de massa de mil grãos e de produtividade foram comparadas pelo teste Tukey a 5\% de probabilidade. A dessecação no estádio fenológico $\mathrm{R}_{8}$ não apresentou redução de umidade significativa quando comparada com o controle. A dessecação no estádio fenológico $\mathrm{R}_{6}$ reduziu a massa de mil grãos e a produtividade da soja. $\mathrm{O}$ posicionamento da dessecação no estádio $\mathrm{R}_{7}$ possibilitou redução de umidade com a antecipação de colheita, sem prejuízos na produtividade da cultura. A dessecação química da soja com o herbicida Diquat no estádio reprodutivo $\mathrm{R}_{7}$ antecipa a colheita dos grãos com redução da umidade da planta sem prejuízo na massa seca acumulada e na produtividade.
\end{abstract}

Palavras-chave: Glycine max. Maturação Fisiológica. Dessecação. Colheita.

\begin{abstract}
The pre-harvest desiccation in soybean crops has been increasingly used, as it provides benefits such as early harvest, weed control and greater uniformity in crop maturation. However, the application of the herbicide must be placed in the phenological stages of the crop that does not harm the grain filling and, consequently, the productivity. Thus, this study aimed to evaluate the effect of applying Diquat desiccant, at different reproductive stages, on moisture loss and productivity and the consequent anticipation of soybean harvest. The experiment was installed in a homogeneous area in a completely randomized design, with three replications. The treatments tested were application of the herbicide Diquat at stages $R_{6}, R_{7}$ and $R_{8}$ and a control without herbicide application. The variables analyzed were the moisture content of the grains after desiccation, the mass of a thousand grains and yield. Data were subjected to analysis of variance. Moisture content means were compared,

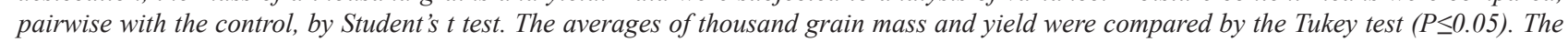
desiccation in the $R_{8}$ phenological stage did not show significant moisture reduction when compared to the control. Desiccation at the $R_{6}$ phenological stage reduced the mass of a thousand grains and soybean yield. The positioning of desiccation at stage $R_{7}$ allowed a reduction of moisture with the possibility of anticipating harvest, without harming crop yield Chemical desiccation of soybeans with the herbicide Diquat at the $R_{7}$ reproductive stage anticipates the harvest of grains, reducing plant moisture without harming accumulated dry mass and productivity
\end{abstract}

Keywords: Glycine max. Physiological Maturation. Desiccation. Harvest.

\section{Introdução}

A soja (Glycine max) é a principal cultura do agronegócio brasileiro e está entre as mais importantes do mundo. O crescimento da produção nacional de soja está atrelado ao desenvolvimento tecnológico e ao melhoramento genético da cultura, como mecanização de todas as etapas do cultivo, desenvolvimento de cultivares adaptadas e mais resistentes às adversidades encontradas nas áreas de produção, práticas de manejos tanto de solo quanto fitossanitárias e reduções de perda na colheita (FREITAS, 2011).

Com todos esses avanços, o Brasil é o maior produtor mundial de soja, com uma produção recorde, na safra 2020/21, de 135.540,3 milhões de toneladas com uma área cultivada de 38.473,0 mil hectares no território nacional (CONAB, 2021). No entanto, mesmo com safra recorde e aumento da produção do grão, o retardamento da colheita provocado pelas condições climáticas do país, trouxe consequências econômicas devido à falta de produto no mercado em alguns períodos e excesso de concentração de produtos nos portos em outro período (CONAB, 2021).

Nesse contexto, uma prática cultural difundida nos campos de soja é a aplicação de herbicidas dessecantes na pré- 
colheita. A dessecação da cultura na pre-colheita auxilia na rápida secagem e perda das folhas, e vem ganhando cada vez mais adesão pelos produtores de todo o mundo, principalmente em regiões onde são registradas altas temperaturas e altos índices pluviométricos (GUIMARÃES et al., 2012). Nessas condições, é necessário que a cultura seja colhida o quanto antes, evitando que as lavouras fiquem expostas as condições climáticas adversas, e sofram prejuízos na qualidade dos grãos à campo.

A aplicação de herbicidas dessecantes no estágio correto é de extrema importância, pois se a mesma for realizada antes da cultura atingir o ponto de maturidade fisiológica pode ocasionar reduções significativas de produtividade. No entanto, épocas de aplicação do herbicida pós-maturidade fisiológica não apresentam redução de produtividade da cultura (PELÚZIO et al., 2008). Na cultura da soja, essa maturação é desuniforme, sendo observadas alterações na massa de matéria seca, teor de água, tamanho, germinação e vigor (MARCOS FILHO, 2005).

Segundo Inoue et al. (2012), a partir do estádio fenológico $\mathrm{R}_{7}$, os grãos já acumularam uma porção considerável de matéria seca, caracterizando a maturidade fisiológica e possibilitando a aplicação de herbicidas dessecantes sem que a produtividade seja alterada negativamente. Para as cultivares de soja que apresentam características de crescimento indeterminado, a decisão do momento de se realizar a dessecação deve ser ainda mais criteriosa, uma vez que essas apresentam um maior período de desenvolvimento e emissão de vagens que as variedades de crescimento determinado, ocasionando maior desigualdade de fases de desenvolvimento de vagens em uma só planta (ZAGONEL, 2005).

Dessa forma, o presente trabalho teve como objetivo avaliar o efeito da aplicação do dessecante Diquat, em diferentes estádios reprodutivos, sobre a perda de umidade e a produtividade e a consequente antecipação da colheita da soja.

\section{Desenvolvimento}

\subsection{Metodologia}

O experimento foi realizado na safra 2016/17, em área experimental localizada em Rolândia-PR, que possui Latossolo Vermelho eutroférrico (SANTOS et al., 2018). A caracterização química do solo esta apresentada no Quadro 1. Na área, iniciou-se o cultivo de soja na safra de verão em 1990, em sistema de plantio convencional, sucedido com trigo na safra de inverno. A partir do ano de 1998, com a difusão das novas tecnologias (e.g. plantio direto, zoneamento de risco agroclimático, manejo integrado para controle fitossanitário, rotação de culturas, manejo conservacionista), adotou-se na área o sistema de plantio direto, com rotação de culturas de milho e soja no verão, e trigo e milho segunda safra no inverno. No ano de 2014, implantou-se na safra de inverno o cultivo consorciado de milho com Urochloa ruziziensis.

Quadro 1 - Características químicas do solo da área experimental

\begin{tabular}{|c|c|c|c|c|c|c|c|c|c|c|c|}
\hline \multirow[b]{2}{*}{ Amostra } & $\mathbf{P}$ & $\mathbf{C}$ & & Al & $\mathbf{H}+\mathbf{A l}$ & $\mathrm{Ca}$ & Mg & $\mathbf{K}$ & SB & $\mathbf{T}$ & \multirow{2}{*}{$\begin{array}{l}\mathrm{V} \\
\%\end{array}$} \\
\hline & $\begin{array}{l}\mathrm{mg} \mathrm{dm}^{-3} \\
\text { solo }\end{array}$ & $\begin{array}{c}\mathrm{g} \mathrm{dm}^{-3} \\
\text { solo }\end{array}$ & pH & \multicolumn{7}{|c|}{ 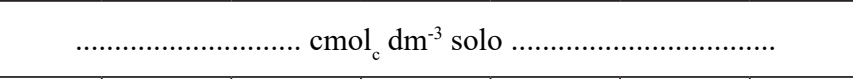 } & \\
\hline Solo experimento & 11,35 & 15,55 & 6,2 & 0.00 & 3,55 & 6,23 & 2,11 & 0,52 & 8,86 & 12,4 & 71,4 \\
\hline
\end{tabular}

O experimento foi instalado em área homogênea de topografia plana, em delineamento inteiramente casualizado, com 3 repetições. As parcelas foram instaladas com $25 \mathrm{~m}^{2} \mathrm{e}$ os tratamentos testados foram: T1: controle sem aplicação de herbicida; T2: aplicação de herbicida no estádio $\mathrm{R}_{6}$; T3: aplicação de herbicida no estádio $R_{7}$ e T4: aplicação de herbicida no estádio $\mathrm{R}_{8}$.

A cultivar utilizada foi a TMG 7062 IPRO ${ }^{\circledR}$ RR2, indicada para as regiões produtoras de soja no norte do Paraná, que recebeu tratamento de sementes com fungicida e inseticida, caracterizado pela utilização dos ingredientes ativos piraclostrobina $25 \mathrm{~g} \mathrm{~L}^{-1}$, tiofanato metílico 225 $\mathrm{g} \mathrm{L}^{-1}$ e fipronil $250 \mathrm{~g} \mathrm{~L}^{-1}$ (Standak Top ${ }^{\circledR}, 2 \mathrm{~mL} \mathrm{~kg}^{-1}$ de i.a., FS, BASF). As sementes também foram inoculadas com Bradyrhizobium japonicum e B. elkanii (cepas SEMIA 5079 e 5019, respectivamente), na dose de $8 \mathrm{~g} \mathrm{~kg}^{-1}$ de semente (Masterfix Soja, 5·10 UFC g $^{-1}$, Stoller do Brasil Ltda.). A semeadura foi realizada de forma mecanizada, com auxílio de uma semeadora-adubadora, com espaçamento entre linhas de 0,45 m, e densidade de semeadura de 11 sementes $\mathrm{m}$ linear ${ }^{-1}$, proporcionando uma população de 244.000 plantas $\mathrm{ha}^{-1}$. A adubação mineral de base, no sulco de semeadura, foi de $260 \mathrm{~kg} \mathrm{ha}^{-1}$ do formulado NPK 06-24-12. Durante o desenvolvimento das plantas, o manejo fitossanitário foi realizado com uso de defensivos agrícolas recomendados agronomicamente, conforme as recomendações da Embrapa (2005).

O herbicida usado para dessecação foi o Diquat $200 \mathrm{~g}$ $\mathrm{L}^{-1}$ (Reglone®, $10 \mathrm{~mL} \mathrm{~L}^{-1}$ de i.a., Syngenta). As aplicações do dessecante foram realizadas ao final da tarde, utilizando-se um pulverizador costal, com volume de calda equivalente a $200 \mathrm{~L} \mathrm{ha}^{-1}$. Utilizou-se ponta tipo leque de ângulo de $110^{\circ}$, e vazão de $0,5 \mathrm{~L} \mathrm{~min}^{-1}$. Na calda, foi adicionado como adjuvante $0,5 \%$ de óleo mineral para facilitar a absorção do produto pela cutícula da folha.

A identificação dos estádios reprodutivos para cada tratamento foi baseada na escala de Fehr e Caviness (1977), quando $50 \%$ da população de plantas atingiram o estádio 
desejado.

As variáveis analisadas foram umidade dos grãos, massa de 1000 grãos e produtividade. A redução no teor de água dos grãos foi verificada após dez dias da aplicação do herbicida, respeitando o intervalo de segurança de 7 dias conforme instruções contidas na bula do fabricante. Para isso, foram coletadas dez plantas das 3 linhas centrais de cada parcela experimental, considerada como área útil nas análises, nas quais as vagens foram trilhadas manualmente, e em seguida, as amostras de grãos seguiram para o laboratório para determinação da sua umidade, pelo método de secagem em estufa a $105^{\circ} \mathrm{C}$ por $24 \mathrm{~h}$, até obtenção de massa constante e, assim, determinado o teor de umidade contido em cada amostra (BRASIL, 2009).

Para a determinação da massa de 1000 grãos, foram coletadas 10 plantas de forma aleatória na área útil de cada parcela, que foram trilhadas manualmente, formando-se três amostras de 200 sementes por parcela. Em seguida, determinou-se a massa de cada amostra, em balança analítica de precisão $(0,01 \mathrm{~g})$, e na sequência, obteve-se a massa média de 200 grãos por parcela. Posteriormente, por extrapolação, determinou-a massa de 1000 grãos (BRASIL, 2009). Posteriormente, determinou-se a umidade das amostras em medidor de umidade $\mathrm{GAC}^{\circledR}$, e assim, foi calculada a massa de 1000 grãos considerando a umidade corrigida para $13 \%$ (BRASIL, 2009).

A produtividade foi estimada através da coleta de todas as plantas de duas linhas centrais de cada parcela por 3 metros lineares, compreendendo $2,7 \mathrm{~m}^{2}$. As plantas foram trilhadas manualmente e os grãos pesados, sendo os resultados transformados em $\mathrm{kg} \mathrm{ha}^{-1}$, e corrigidos para $13 \%$ de umidade
(BRASIL, 2009).

Os dados foram submetidos a análise de variância, e as médias comparadas pelo teste Tukey $(P \leq 0,05)$. Os dados de eficácia da dessecação foram comparados em pares com o controle pelo teste $\mathrm{t}$ de Student. O software utilizado para análises estatísticas foi o SASM-Agri (CANTERI et al., 2001).

\subsection{Teor de umidade}

A redução no teor de umidade dos grãos da soja com a dessecação foi influenciada pelo estágio reprodutivo de aplicação do herbicida dessecante (Figura 1). A dessecação nos estádios $\mathrm{R}_{6}$ e $\mathrm{R}_{7}$ apresentaram redução significativa do teor de umidade nos grãos, colhendo-se com 10 e $12,5 \%$ respectivamente, quando comparadas com o tratamento controle que se encontravam com 40 e $23 \%$ de umidade $(P \leq 0,01)$. A colheita realizada 10 dias após a dessecação no estádio $\mathrm{R}_{6}$ obteve perda de $30 \%$ no teor de umidade dos grãos e no estádio $\mathrm{R}_{7}$, de 10,5\%. De acordo com Zagonel (2005), os herbicidas proporcionaram uma expressiva perda de água da biomassa verde da planta, antecipando a desidratação das sementes e ocasionando antecipação da colheita. Lacerda et al. (2003) também observaram reduções significativas no teor de umidade de plantas dessecadas em estádio $\mathrm{R}_{7}$ quando comparadas às plantas sem dessecação.

A dessecação no estádio $\mathrm{R}_{8}$ não apresentou redução de umidade significativa quando comparada com o controle, ambos colhidos com $11 \%$ de umidade. Segundo Lacerda et al. (2003) isso pode estar relacionado ao processo de secagem natural que as plantas sofrem ao ficarem no campo até o estágio $R_{8}$.

Figura 1 - Teor de umidade dos grãos após dessecação em diferentes estádios reprodutivos em comparação com plantas controles
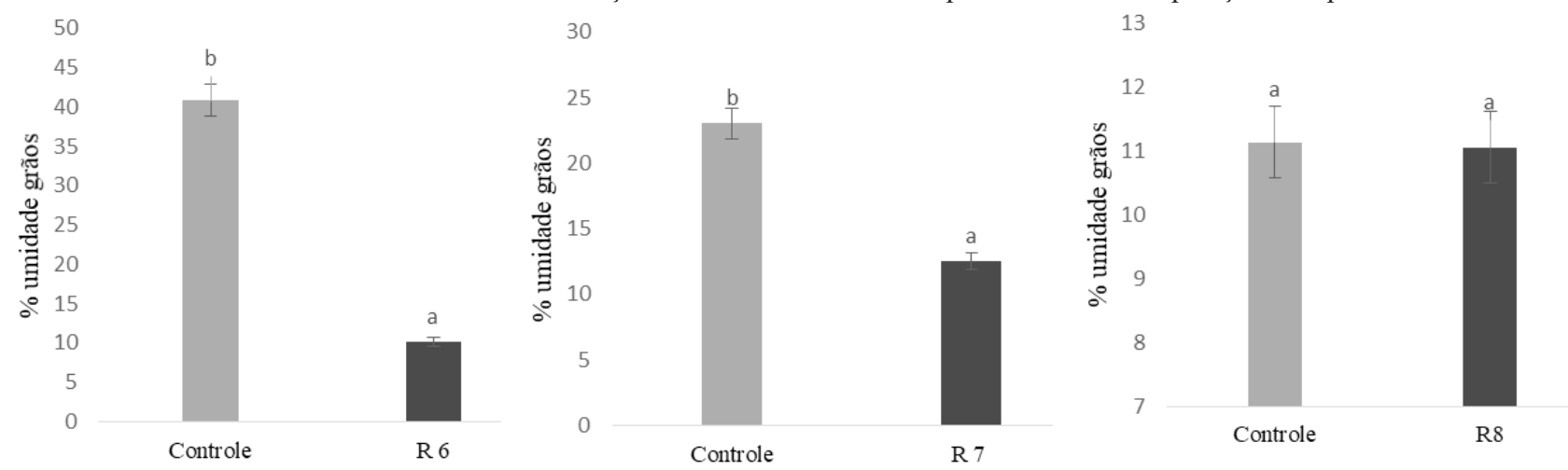

Fonte: Dados da pesquisa.

\subsection{Peso de mil grãos e produtividade}

O peso de mil grãos e a produtividade da soja também foram influenciados pela época de aplicação do herbicida para dessecação (Quadro 2). A soja quando dessecada nos estádios $R_{7}$ e $R_{8}$, manteve valores de massa dos grãos e de produtividade, daqueles observados no tratamento controle, sem aplicação do dessecante. Todavia, a dessecação no estádio
$\mathrm{R}_{6}$, acarretou em reduções na massa dos grãos e também na produtividade da cultura, devido a deposição anormal de reserva nos grãos, ocasionada pela aceleração da maturação pós-dessecação em fase fenológica não adequada. Albrecht et al. (2008) também reportaram redução da produtividade de grãos de soja no Oeste do Paraná em condições de campo que aceleraram a maturação da cultura. 
Quadro 2 - Massa de mil grãos e produtividade da soja, cultivar TMG 7062 IPRO $^{\circledR}$ RR2 em função dos estádios reprodutivos de dessecação

\begin{tabular}{|l|c|c|}
\hline \multirow{2}{*}{$\begin{array}{l}\text { Época de } \\
\text { dessecação }\end{array}$} & $\begin{array}{c}\text { Massa de mil } \\
\text { grãos }\end{array}$ & Produtividade \\
\cline { 2 - 3 } & $\mathbf{( g )}$ & kg ha $^{-1}$ \\
\hline Controle & $198,8 \mathrm{a}$ & $4359,2 \mathrm{a}$ \\
\hline R6 & $162,3 \mathrm{~b}$ & $3058,0 \mathrm{~b}$ \\
\hline R7 & $190,2 \mathrm{a}$ & $4003,2 \mathrm{a}$ \\
\hline R8 & $190,0 \mathrm{a}$ & $4236,3 \mathrm{a}$ \\
\hline CV (\%) & 2,85 & 4,51 \\
\hline
\end{tabular}

Fonte: Dados da pesquisa.

Pereira et al. (2009) também apontaram queda significativa da massa de mil grãos com o posicionamento da dessecação com Diquat no estágio $R_{6}$, o que indica que a planta ainda acumula massa nos grãos após esse estádio. Redução de $35 \%$ na produtividade da soja dessecada em $\mathrm{R}_{6}$ com herbicida Paraquat, também do mecanismo de ação de inibidores de fotossistema I, foi encontrada por Lamego et al. (2013). Pelúzio et al. (2008) apontaram prejuízos na produtividade da soja quando dessecada com o herbicida Paraquat no estádio $\mathrm{R}_{6}$.

Assim como observado neste estudo, Inoue et al. (2012) afirmaram que a partir do estádio $\mathrm{R}_{7}$, os grãos já acumularam uma porção considerável de matéria seca, caracterizando a maturidade fisiológica e possibilitando a aplicação de herbicidas inibidores de fotossistema I para dessecação sem que a massa dos grãos seja alterada negativamente.

Os resultados indicaram uma relação diretamente proporcional dos valores de massa de mil grãos e produtividade, sendo que a aplicação de dessecante nos estádios $R_{7}$ e $R_{8}$ não acarretaram prejuízos para a soja. De acordo com Silva (2006), épocas de aplicação do herbicida para dessecação pós-maturidade fisiológica não apresentaram redução de produtividade da cultura, pois nesse estágio a semente já não possui mais ligações fisiológicas com a planta-mãe, de modo que o aporte de nutrientes já tenha sido interrompido naturalmente.

No tratamento no qual foi posicionada a aplicação do herbicida dessecante no estágio $\mathrm{R}_{6}$, embora tenha sido observada redução nos teores de umidade dos grãos e possibilidade de antecipação da colheita, a dessecação afetou negativamente a massa dos grãos e a produtividade da cultura. Nesse estádio, a soja ainda não atingiu maturidade fisiológica, com translocação de fotoassimilados ainda ocorrendo para as sementes. Segundo Kappes, Carvalho e Yamashita (2010), a aplicação de herbicidas dessecantes antes da soja atingir o ponto de maturidade fisiológica pode ocasionar reduções significativas de produtividade. Assim, os resultados obtidos nesse estudo, e também na literatura, evidenciaram que a dessecação da soja no estádio $R_{6}$, visando antecipação da colheita, é uma prática prejudicial que traz prejuízos na produtividade da cultura.

Embora a dessecação da soja no estádio $\mathrm{R}_{8}$ não tenha acarretado prejuízos na massa de grãos e na produtividade da cultura, nesse estádio também não houve redução da umidade que garantisse antecipação na colheita, o que inviabilizou sua aplicação para tal finalidade. Foi observado que no estádio $R_{8}$ a planta já se encontrava em estágio avançado de maturação, e naturalmente passando pelo processo de secagem no campo. Assim, foi verificado pouca possibilidade de ação do herbicida dessecante, devido à ausência de tecido com alto teor de umidade, o que tornou desnecessária e inviabilizava economicamente a aplicação de herbicidas dessecantes nesse estádio reprodutivo.

Experimentos realizados por Veiga (2007) utilizando Paraquat e Diquat na dosagem de 2,0 L.ha ${ }^{-1}$ propiciaram a antecipação da colheita entre 10 a 15 dias, sem redução de produtividade, e sem a presença de resíduos químicos dos herbicidas nos grãos de soja. Pereira et al (2015) indicaram a dessecação da soja no estádio $\mathrm{R}_{7}$, pois antecipou a colheita em 6 dias e manteve a produtividade, como também observado neste estudo. Zuffo et al. (2020) observaram que o dessecante Diquat (na dose de 1,5 $\mathrm{L} \mathrm{ha}^{-1}$ ) proporcionou menores danos fisiológicos às sementes de soja quando comparados a outros herbicidas. Os autores ainda consideram que a dessecação traz como vantagens, além da antecipação da colheita, a possibilidade de contornar possíveis problemas climáticos na colheita, auxílio no controle de plantas daninhas e facilidades na implantação da cultura sucessora.

\section{Conclusão}

A dessecação química da soja com o herbicida Diquat no estádio reprodutivo $\mathrm{R}_{7}$ antecipa a colheita dos grãos, possibilitando redução significativa da umidade da planta, sem prejuízo no enchimento dos grãos e na produtividade.

\section{Referências}

ALBRECHT, L.P. et al. Teores de óleo, proteínas e produtividade de soja em função da antecipação da semeadura na região oeste do Paraná. Bragantia, v.67, n.4, p.865-873, 2008. doi: 10.1590/ S0006-87052008000400008

BRASIL. Ministério da Agricultura e Reforma Agrária. Secretaria Nacional de Defesa Agropecuária. Departamento Nacional de Produção Vegetal. Coordenação de Laboratório Vegetal. Regras para Análise de Sementes. Brasília: MS, 1992.

BRASIL. Ministério da Agricultura, Pecuária e Abastecimento. Regras para análise de sementes. Ministério da Agricultura, Pecuária e Abastecimento. Secretaria de Defesa Agropecuária. Brasília: MAPA, 2009.

CÂMARA, G.M.S. (Ed.). Soja: tecnologia da produção. Piracicaba: ESALQ, 1998.

CANTERI, M.G. et al. SASM - Agri : Sistema para análise e separação de médias em experimentos agrícolas pelos métodos Scoft - Knott, Tukey e Duncan. Rev. Bras. Agrocomputação, v.1, n.2, p.18-24, 2001.

CONAB - Companhia Nacional de Abastecimento. Acompanhamento da safra brasileira de grãos. 2021. Disponível em: <https://www.conab.gov.br/info-agro/safras/graos/boletimda-safra-de-graos > Acesso em: 31 ago. 2021.

EMBRAPA SOJA. Tecnologias de produção de soja - Região 
Central do Brasil, 2005. Londrina: Embrapa Soja, 2005.

EMBRAPA. Centro Nacional de Pesquisa de Solos. Sistema brasileiro de classificação de solos. Brasília: EMBRAPA, 1999. $412 \mathrm{p}$.

FEHR, W.R.; CAVINESS, C.E. Stages of soybean development. Ames, Yowa: Yowa State University of Science and Technology, 1977.

FREITAS, M.C.M. A cultura da Soja no Brasil: O crescimento da produção Brasileira e o surgimento de uma nova fronteira agrícola. Rev. Enciclop. Biosfera, v.7, n.12, p.1-12, 2011.

GUIMARÃES, V. F. et al. Produtividade e qualidade de sementes de soja em função de estádios de dessecação e herbicidas. Rev. Planta Daninha, v.30, n.3, p. 221. 2012. doi: 10.1590/S010083582012000300012

INOUE, I. H. et al. Determinação do estádio de dessecação em soja de hábito de crescimento indeterminado no Mato Grosso. Rev. Bras. Herbicidas, v.11, n.1, p.71-83, 2012. doi: 10.7824/rbh. v11i1.137

KAPPES, C.; CARVALHO, M.A.C.; YAMASHITA, O. M. Potencial fisiológico de sementes de soja dessecadas com diquat e paraquat. Scie. Agraria, v.10, n.1, p.1-6, 2010. doi: 10.5380/rsa.v10i1.12520

LACERDA, A.L.S. et al. Aplicação de dessecantes na cultura da soja: teor de umidade nas sementes e biomassa nas plantas. Planta Daninha, v.21, n.3, p. 427-434, 2003. doi: 10.1590/ S0100-83582003000300011

LAMEGO, F.P. et al. Dessecação pré-colheita e efeitos sobre a produtividade e qualidade fisiológica de sementes de soja. Planta Daninha, v.31, n.4, p.929-938, 2013. doi: 10.1590/S0100-

\section{9}

MARCOS FILHO, J. Fisiologia de sementes de plantas cultivadas. Piracicaba: FEALQ, 2005.

PELÚZIO, J. M. et al. Influência da dessecação química e retardamento de colheita na qualidade fisiológica de sementes de soja no sul do estado do Tocantins. Biosc. J., v.24, n.2, p.77-82, 2008.

PEREIRA, T. et al. Diversity in common bean landraces from South Brazil. Acta Bot. Croatica, v.68, n. 1, p. 79-92, 2009. doi: $10.5965 / 223811711832019474$

PEREIRA, T. et al. Dessecação química para antecipação de colheita em cultivares de soja. Semina Ciênc. Agrárias, v. 36, n. 4, p. 2383-2394, 2015. doi: 10.31413/nativa.v7i1.6613

SANTOS, H.G. Sistema Brasileiro de Classificação de Solos. Brasília: EMBRAPA, 2018.

SILVA, P.A. Estudo da qualidade fisiológica, bioquímica e ultraestrutural, durante o desenvolvimento e a secagem de sementes de soja. Lavras: Universidade Federal de Lavras, 2006

VEIGA, A.D. et al. Tolerância de sementes de soja à dessecação. Ciênc. Agrotecnol., v.31, n.3, p.773-78, 2007. doi: 10.1590/ S1413-70542007000300025

ZAGONEL, J. Herbicide application timing in preharvest desiccation of soybean cultivars with different growth habits. J. Environ. Scie, v.B40, n.1, p.21-28, 2005. doi: 10.1081/PFC200034198

ZUFFO, A. M. et al. Épocas de colheita com dessecação química e suas relações com a qualidade fisiológica e expressão enzimática em sementes de soja. Rev. Caatinga, v.33, n.2, p.361-370, 2020. doi: 10.1590/1983-21252020v33n209rc 